\title{
INTENTION TO CONSUME JUNK FOOD: A STUDY OF DRIVERS FOR CONTROL IMPLICATIONS
}

\author{
EKTA DUGGAL* \\ Motilal Nehru College, University of Delhi, India \\ HARSH V. VERMA \\ Faculty of Management Studies, University of Delhi, India \\ *Corresponding Author: ekta@mln.du.ac.in
}

\begin{abstract}
Junk food has been making fast inroads in Indian market. Socio-culturally India has been a collectivist and tradition dominated society, where the concept of food is very different from junk food. This study aims to explore the rising incidence of junk food based on the theory of planned behavior and contributes to understanding the consumption drivers for possible social marketing implications. The findings suggest that out of the three constructs: attitude, social norms and perceived behavioral control, only perceived behavioral control was found to be the significant determinant of intentions. The study has implications for social marketers. For controlling the rising incidence of junk food, the strategy should focus on developing a sense of perceived control. This requires building self-belief and increasing barriers to access of junk food. This paper contributes to the body of literature in understanding consumption drivers of junk food, particularly in a collectivist and family oriented society like India and how efforts to control rising incidence of junk food can be made more effective.
\end{abstract}

Keywords: Junk food, Social norms, Neural network, Hedonism, Nutritional value.

Published: 14/7/2019

\section{Introduction}

Certain products embody a clash between pursuit of profit and interests of society. Food consumption has evolved from being a necessity for survival to a playground of hedonic indulgence. Smith (2007) defines junk foods as commercial with low nutritional value but with high salt, calories, and fat. Marketing and branding cleverly legitimizes junk food or calorie dense foods by constructing socio-psychological meanings around their consumption. This often compromises social well-being. The packaged hedonism (Cronin \& McCarthy, 2011; Khan et al., 2005) and symbolism (Schor \& Ford, 2007) in this category of food jeopardizes health, same as cigarettes and alcohol do (Smith, 2006). The incidence of several diseases like hypertension, diabetes and high cholesterol are linked to fast food consumption (Stanley et al., 2009).

Marketing is fundamentally about development of creation value in response to evolving consumer demand (Kotler \& Armstrong, 2004). Junk food is born out of responsiveness to need for convenience (He et al., 2012) and social representation (Schor \& Ford, 2007). Junk food's value stems from class signification, time 
saving and hedonic gratification (Marino, 2004; Raloff, 1996). This category of food is harmful because it alters the food's coordinates away from health and nutrition to, fun and pleasure (Hawkes, 2002; Schlosser, 2001).

The growing popularity of junk food is undesirable from welfare perspective. Changing consumer behavior in favor of social good is difficult to achieve (Aronson \& Gonzales, 1990; Costanzo et al., 1986) because it is rooted in desires and preferences. Therefore, the strategy to counter undesirable behaviors must be based on a planned approach (ISMA, ESMA and AASM, 2013; Kotler \& Zaltman, 1971). There are two ways to achieve behavior change. One approach is to make undesirable behaviors difficult to execute like by imposing of tax (Business Standard, 2016; Mytton \& Rayner, 2012). In this regard, WHO urges nations to take legal route to curb junk food consumption (Ettinger, 2014). But these types of interventions are contentious (Sahadi, 2015) for being coercive.

The other strategy focuses on influencing behavior voluntarily (Donovan \& Henley, 2003; Kotler \& Lee, 2008). The promotion of voluntary behavior change must be based on behavioral insights (Hastings, 2003; Kotler \& Levy, 1971). Behaviors are influenced by consumer psychology and culture. Integration of consumer centric thinking and behavioral insights are essential starting points for driving sustainable behavioral change (Gordon et al., 2016; Lourenço et al., 2016b). The social change strategies must be based on insights drawn from relevant theoretical models (Lefebvre, 2011). In this regard, Fishbein and Ajzen's (1980) theory of planned behavior (TPB) is relevant to study consumer behavior.

TPB proposes that intention to engage in a behavior is determined by attitude towards behavior, subjective norm and perceived behavioral control (Ajzen, 1988). Achieving behavioral change is difficult (MacFayden et al., 1999) because they are anchored in attitudes. Attitude is internal disposition to react in a particular way (Eagly \& Chaiken, 1993). In addition to attitude, TBP (Fishbein \& Ajzen,
1980), Ajzen (1985) proposes that intention to behavior is determined by two more factors namely social norms and perceived behavioral control. Three things common to junk food marketing are hedonistic gratification, social approval and ease of consumption which correspondingly reflect attitude, social norms and perceived behavioral control. Logically, junk foods make little sense; therefore, junk foods are sold on social and hedonistic appeals (Cronin \& McCarthy, 2011; Khan et al., 2005) and by promoting ease of consumption.

TPB has been widely employed to study a variety of volitional behaviors (Ryan \& Bonfield, 1980), including blood donation intentions (Armitage \& Conner, 2001; Giles \& Cairns, 1995), online course adoption (Knabe, 2009), teacher's intentions to use computers (Lee et al., 2010) condom use (Carmack \& Lewis-Moss, 2009) and recycling behavior (Tonglet et al., 2004). Specifically, TPB has been used to study healthy eating behavior (Fila \& Smith, 2006), food choice (Ajzen, 2015; Dennison \& Shepherd, 1995) and barriers to healthy eating (Grønhøj et al., 2012). TPB has been used in several contexts but mostly in developed countries (Dutta \& Singh, 2014). The previous studies on food in Indian context explored consumers' perceptions about fast food (Goyal \& Singh, 2007), consumption among children (Kaushik et al., 2011), correlates of overweight and obesity (Goyal et al., 2011, Kalra \& Unnikrishnan, 2012), determinants of choice (Anand, 2011) and regulations (Khandelwal \& Reddy, 2013). But there have been few attempts to explore junk food consumption using TPB in India. Furthermore, the contribution of attitude, social norms and perceived behavioral control is expected to vary across different conditions (Miller et al., 2004). In this background, this study was undertaken with the following objectives in consideration: to explore the role of three constructs proposed in TBP in explaining intention to consume junk food and to study the effectiveness of slogan based strategy in reversing the intention to behave in socially undesirable way, like, point of purchase 
warnings in case of cigarettes and suggestion to obey traffic rules on roadside. These findings can help agencies who seek to curb junk food consumption by designing appropriate control strategies.

\section{Literature Review}

\section{Junk Food and Health}

The phenomenon of junk food is like a ticking time bomb which will sooner or later explode into an obesity epidemic (Datar \& Nicosia, 2012). It is linked with diseases like colorectal cancer, obesity and high cholesterol (Bhaskar, 2012). Obesity and weight problems are linked to fast food (Birch \& Anzman, 2010; Bowman et al., 2004; Wang et al., 2009) and these have reached alarming levels (Witkowski, 2007). Obesity is associated with a range of diseases including type 2 diabetes, hypertension and cardiovascular disease (Finkelstein et al., 2005; Kihara \& Matsuzawa, 2015). The damage to health is caused by excessive amounts of carbohydrates, sugar, un-healthy fats and salt (Berg, 2016) and high calories (Stender et al., 2007). Junk food is also responsible for increased risk of dementia, memory and learning problems, loss of appetite (NDTV, 2017) and addictiveness (Arumugam, 2015).

Children, particularly, are vulnerable to fast food advertising and promotions (Brownell et al., 2009; Vadehra, 2010) and their targeting is a major cause of childhood obesity (Jaisheeba et al., 2012). Junk food consumption increases as kids move to higher classes (Gohain, 2017). Ironically fast food advertising is 'disastrously effective' (Resseler, 2013) and it targets children and the young. Food choice is a matter of autonomy and personal decision making (Isobel et al., 2006). It lands on their plate as they gain autonomy over their food choice (Chaplin, 1999). In the US, one third of children and adolescents consume fast food daily (Livingstone, 2005) and are found to be overweight (Ogden \& Carroll, 2010). It burdens national exchequer as huge amount is spent on addressing problems related to excess sugar consumption (Munro, 2013). Rising urbanization and invasion of foreign branded foods is subtly changing food habits in India. This is reflected in growing popularity of burger, pizza, soda, and salty snacks. The fast food industry in India expanding at a very high growth rate of $40 \%$ and is counted as one of the top ten fast food consumers of the world (Shakiran, 2012). This cycle of increasing foot print of branded foods was also witnessed in African countries as they integrated with Western economies (Crisp, 2016).A study in capital city of Delhi found twenty percent of school kids to be overweight (Jha, 2017). Indian consumers are passionate about fast food brands like McDonalds and Pizza Hut (Goyal \& Singh, 2007). These foods owe their popularity among college and school goers to taste, ambience and convenience (Anand, 2011). Eating habit involving consumption of junk food, chocolate and eating out contribute to problems of obesity (Goyal et al., 2010).

With increasing integration of African countries with world economy, these economies also face challenge of harmful health effects of due to introduction of junk food media, business and social environment are major contributors to rising prevalence of obesity. Junk food companies prefer to ignore externalities of their business (Institute of Medicine, 2006). In order to minimize externalities, a strategy effective in equal measure is needed to counter incidence of junk foods and it is imperative on nations to create conditions that ensure health of their kids and youth (Fineberg, 2006).

\section{Influence of Behavioral Intention to Consume Junk Food on Behavior}

Intention reflects an individual's readiness to engage in a behavior. As per TPB, intentions are better predictor of behavior instead of attitude, subjective norms and perceived behavior control directly (Ajzen, 1988; Ajzen \& Madden, 1986). Intention is the conviction or commitment to carry out a particular action. An individual is likely to intend to engage in a particular behavior if he or she has a positive attitude about the 
behavior; social norms are favorable and have control over that behavior. These constructs are antecedents to intentions which represent a conscious plan to act a particular behavior (Conner \& Armitage, 1998). The psychosocial variables such as attitude and social norms better predict intentions than demographics (Robinson \& Smith, 2002).

\section{Influence of Attitude on Behavioral Intention to Consume Junk Food}

Although home-cooked food is a norm in India, yet this practice is fast getting replaced by other kinds of foods (National Institute of Nutrition, 2010).This shift away from traditional foods is driven by a pull based on sensory pleasure (Cronin \& McCarthy, 2011), social legitimacy (Schor \& Ford, 2007) and ease of consuming (He et al., 2012).Indian society has been traditional, family oriented and collectivist. Collectivism implies social norms and common beliefs that have imprint on individual behaviors (Triandis, 1994). The food choices, consumption times and process of preparation are determined by family traditions and culture (Fuller, 2017). The concept of food sits on the bedrock of cultural values, beliefs, traditions and faith which are likely to drive an individual's attitude towards things of consumption. Values influence consumer decision making including product choice (Engle et al., 1995) and motivate action (Schwartz, 1994). Since, junk food stands in direct opposition of home cooked food in terms of preparation, the preparer, presentation and the recipe, this category of food is likely be unfavorably viewed. As proposed in the TPB that attitude drives intentions, a negative attitude is expected toward intention to consume junk food.

\section{Influence of Social Norms on Behavioral Intention to Consume Junk Food}

In South Asian cultures, food is a metaphor of care and nurturing relationship between mother and child (Srinivas, 2006). Further, being a collectivist society, the family and cultural values exert conformity in favor of sanctioned foods. Studies report that food preferences and habits conform to foods that are made and consumed at family level (Birch, 1988; Rozin et al., 1984) and food's appropriateness is determined socially (Herman et al., 2002). The cultural practices and norms impact thinking and behavior (Reynolds et al., 2014) and create pressure to conform.

The connection between social norms and intention has been explored in various studies. Social norms were found to be an important driver of intention to adopt e-learning (Hartwick \& Barki, 1994); fast food consumption (Bagozzi et al., 2000); sustainable food consumption (Vermeir \& Verveke, 2006) healthy food (Dutta $\&$ Singh, 2014) and blood donation (Giles et al., 2004). Food in India is culturally constructed and is associated with piety, health, class and hierarchy (Varman, 2017).Conceptually junk food is radically different from concept of food in India which is rooted in family and sociocultural traditions (Appadurai, 1988). Junk food neither conforms to culture nor to family traditions. Accordingly, a negative relationship is hypothesized between social norms and intention to consume junk food.

\section{Influence of Perceived Behavioral Control on Behavioral Intention to Consume Junk Food}

Lastly, in spite of likelihood of presence of a negative attitude and presence of social norms against junk food, an individual may have intention to consume junk food if it is not within his or her control to what to consume. Perceived behavioral control implies ease or difficulty in performing an act. For instance, a study found that consumer perceived barriers such as lack of availability and inconvenience acted against intention to buy sustainable foods (Robinson and Smith, 2002). The presence or lack of obstacles or lack of has influence on behavioral intentions (Ajzen, 1991). The PBC's influence was found to be significant in intention to dieting (Gardner \& Hausenblas, 2005), practice of weight loss (Schifter \& Ajzen, 1985) and compliance to oddeven air pollution control scheme (Duggal \& Verma, 2016). Accordingly, ease of access and lack of barrier to consume socially determined legitimate food and difficulty of access of junk 
food is likely to affect intentions to consume adversely.

\section{Theoretical Framework and Hypotheses}

The relationships discussed in the preceding paragraphs are shown in Figure 1. The model comprises of five constructs: attitude, social norms, perceived behavioral control, intention to behave and behavior. It is hypothesized that attitude, social norms and perceived behavioral control are antecedents to intention to behave and intention to behave lead to behavior. Testing of these hypotheses can inform social marketers interested in reversing the rising incidence of junk food consumption and thereby enable precise targeting of variables to drive change.

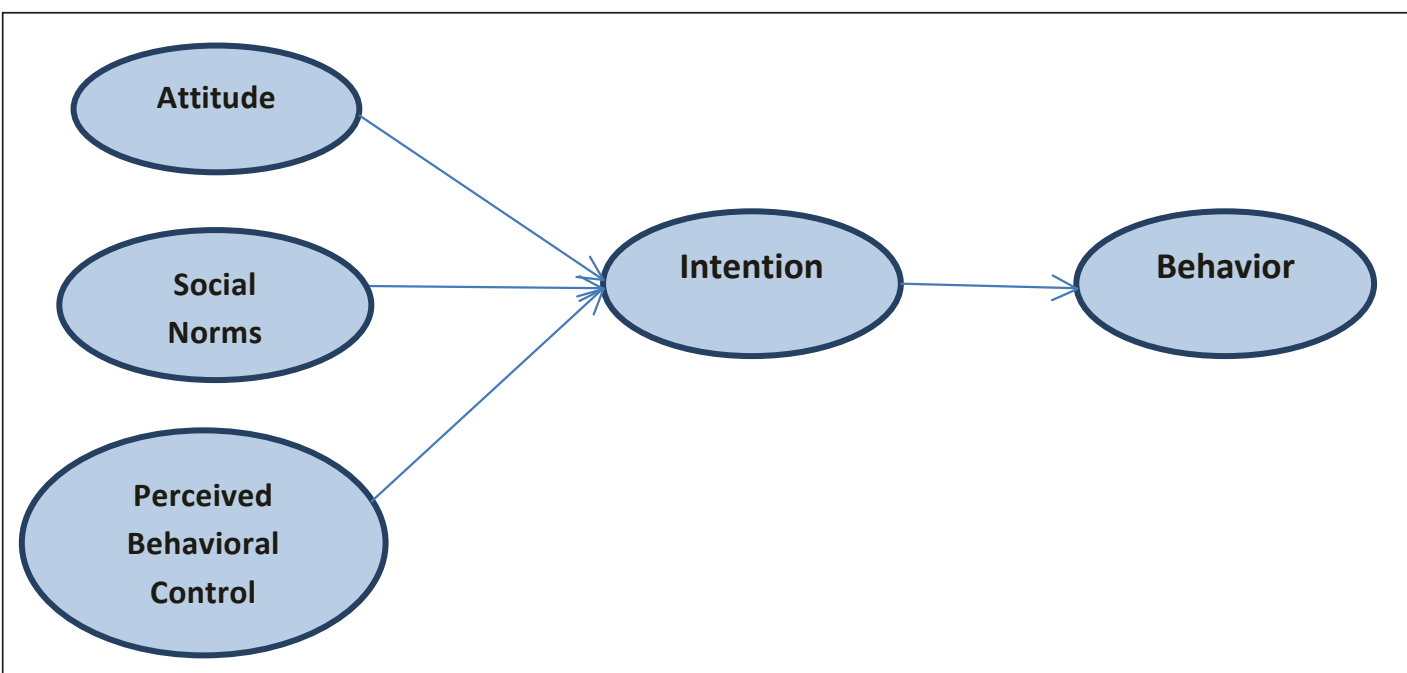

Figure 1. Theoretical Framework

\section{Research Method}

This study was conducted on a sample of young consumers comprising of students of one of India's top universities belonging to the age group of 20-25 years. These participants were enrolled in post graduate courses. A sample of 250 students was chosen purposefully for the study on convenience basis. The data were collected on a brief and unambiguous (Cohen \& Manion, 1980) structured questionnaire using seven point semantic differential scale. The instrument for the study consisted of five scales aimed to measure attitude, social norms, perceived behavioral control, behavioral intention and behavior. These scales were developed as per conceptual and methodological considerations proposed by Ajzen (2006). The respondents in the study were to reveal their position on these scales.

The informants' attitude was measured on twelve seven-point semantic differential items like 'How good or bad the addictive nature of eating junk food is' with one pole being 'very bad' and the other being 'very good'. The scale of subjective norms measured perception of social pressure or influence of significant others in intention to consume junk food. For this, responses were obtained on an eight seven-point semantic differential items which were coded on bi-polar scales like 'approves'/'disapproves' and 'obey'/'disobey'. For instance, 'my family disapproves/approves of my eating junk food'. 
Based on the similar approach, the construct of perceived behavioral control was measured through eight items. The participants provided their responses on a seven point bi-polar measures consisting of items like 'For me living without junk food for days is possible'. The intention to engage in consumption was gauged on four seven point semantic differential scale items like 'I intend to avoid junk food', 'I plan not to have high calorific junk food' and the respondents provided their level of agreement or disagreement on these items. Behavior was measured by two seven point semantic differential items.

An experimental 'before' and 'after', with control group design was adopted. The sample was divided into two matched groups: control group and experimental group. In the experimental group, participants were asked to make a search on 'junk food' on their mobile phone under controlled conditions. A search on 'junk food' produces listings, which, by and large mention adverse effects of junk food on health. It was expected that this would activate firing in neural network of junk food category and trigger recall of associated adverse health effects. This was done to simulate an environment akin to situations when consumer encounters warnings at the point of action as a strategy to dissuade indulgence in undesirable behaviors. This strategy is common to harmful product like cigarette as warning signs are displayed at the sites of cigarette vending ('smoking causes cancer') and harmful behaviors. The clues or primes can turn on associated representations in the memory and enhance their access and spread to related nodes through associative network (Anderson, 1983; Collins \& Loftus, 1975; Higgins et al., 1977). This exposure is likely to surface negative associations developed by social campaigns and cause intentions to dilute. The search time in the experimental groups was limited only to two minutes. This was done deliberately to examine whether clue assisted activation of junk food category would yield an influence on the modeled relationships. This process approximated the low involvement information processing situation by passive recipient (Krugman, 1966). In order to avoid consciousness bias, none of the groups were given specific information on the domain of investigation. Identical instruments were administered on the control and experimental group. The survey data collected on the administered instrument were coded in SPSS and data were quantitatively analyzed to examine relationships between variables.

\section{Findings}

Firstly, internal consistency of the items was assessed through Cronbach alpha with a threshold limit of 0.7 (Nunnally, 1978). Construct items found to be internally inconsistent were removed from the study. Table 1 gives the reliability coefficients of the constructs for the experimental and control group. The coefficients ranged from 0.73 to 0.91 reflecting satisfactory internal consistency.

Table 1

Reliability Coefficients for the Constructs

\section{Constructs}

Reliability Coefficients

Experimental group

Control group

\begin{tabular}{lll}
\hline Attitude & 0.768 & 0.762 \\
Social Norms & 0.776 & 0.732 \\
Perceived Behavioral Control & 0.905 & 0.918 \\
\hline
\end{tabular}


The study used path analysis to estimate the parameters used in the study. The hypotheses were tested using path model as previously done by Joreskog and Sorbom (1996) and Bagozzi et al. (2000). Figure 2 shows the path model to determine the inter-construct relationships. Model estimates were calculated based on ML (maximum likelihood) method through AMOS. The models were subjected to goodness of fit test in order to find the fitness of model with the observed data.

The model fit for the two groups were assessed using normed chi square statistic (CMIN/DF) (to be less than 3.0), the comparative fit index (CFI) (to be greater than or equal to 0.95) and the root mean square error of approximation
(RMSEA) (to be less than or equal to 0.08) as is used in studies (Hu \& Bentler, 1999; Wheaton et al., 1977). An examination of fit indices for the experimental group revealed that the path model had a moderate fit to the observed data. The normed chi square statistic (CMIN/DF) was found to be 2.326, CFI was found to be 0.947 and RMSEA stood at 0.068 . Fit indices for the control group indicated a fair fit of the proposed model. The normed chi square stood at 2.427, CFI score was 0.94 and the value for RMSEA was 0.065 .

The parameter estimates for the two groups are contained in Table 2. The findings were found to be inconsistent with expectations with respect

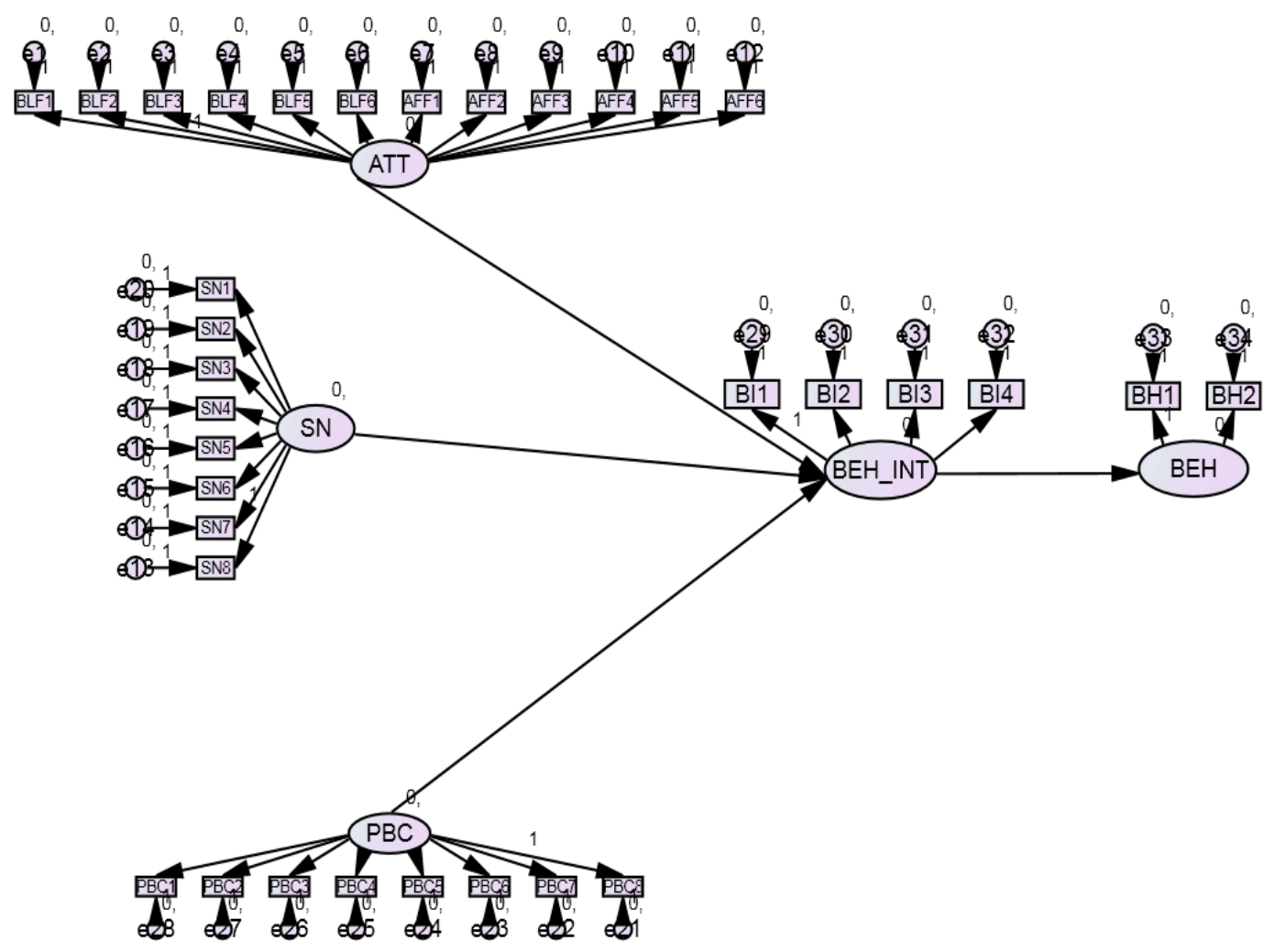

Figure 2. The Path Model Describing Inter-Construct Relationships for the Experimental and the Control Group 
to two antecedents of intention. The attitude and social norm did not show statistically significant relationship with intention for both the control and experimental groups. However, the relationship between perceived behavioral control and intention was found to be significant for both groups. Further, the relationship between intention and behavior was found to be significant for the two groups.

In order to assess whether the search on junk food produced a significant change in the attitude of

Table 2

Standardised Estimates for Hypothesized Relationships: Experimental and Control Group

\begin{tabular}{|c|c|c|c|c|c|c|c|c|c|}
\hline Hypotheses & Relationship & Experimental & froup & & & Control Groul & & & \\
\hline & & $\begin{array}{l}\text { Standardized } \\
\text { Estimate }\end{array}$ & $\begin{array}{l}\text { Standard } \\
\text { Error }\end{array}$ & $\begin{array}{l}\text { Critical } \\
\text { Ratio }\end{array}$ & $\begin{array}{l}\mathrm{P} \\
\text { Value }\end{array}$ & $\begin{array}{l}\text { Standardized } \\
\text { Estimate }\end{array}$ & $\begin{array}{l}\text { Standard } \\
\text { Error }\end{array}$ & $\begin{array}{l}\text { Critical } \\
\text { Ratio }\end{array}$ & $\begin{array}{l}\mathrm{P} \\
\text { Value }\end{array}$ \\
\hline H1 & $\begin{array}{l}\text { Attitudeà } \\
\text { Intention }\end{array}$ & 0.914 & 4.823 & 1.719 & 0.086 & 0.884 & 5.352 & 1.385 & 0.166 \\
\hline $\mathrm{H} 2$ & $\begin{array}{l}\text { Social } \\
\text { Normsà } \\
\text { Intention }\end{array}$ & 0.133 & 0.108 & 1.945 & 0.052 & -0.050 & 0.059 & -0.811 & 0.417 \\
\hline $\mathrm{H} 3$ & $\begin{array}{l}\text { Perceived } \\
\text { Behavioral } \\
\text { Controlà } \\
\text { Intention }\end{array}$ & 0.383 & 0.191 & 4.352 & $* * *$ & 0.464 & 0.072 & 6.884 & $* * *$ \\
\hline $\mathrm{H} 4$ & $\begin{array}{l}\text { Intentionà } \\
\text { Behavior }\end{array}$ & 1.000 & 0.105 & 5.788 & $* * *$ & 1.000 & 0.099 & 7.877 & $* * *$ \\
\hline
\end{tabular}

*** Regression weights significant at $0.1 \%$ significance level.

experimental group a test of difference between means of two groups was performed. Based on the test results, attitude between experimental and control group did not reveal significant difference (Table 3).

T-test analysis for attitude reflects that junk food related search failed to produce a significant change in the attitude of experimental group. This implies that the reminder based marketing strategy like'smoking causes cancer'or road signage reminding drivers to obey traffic rules at the point of behavior probably fails to yield a significant change away from undesirable behaviors. 
Table 3

T-test Analysis for Attitude of Experimental and Control Group

\begin{tabular}{|c|c|c|c|c|c|c|c|c|c|c|}
\hline & & \multicolumn{2}{|c|}{$\begin{array}{l}\text { Levene's } \\
\text { Test for } \\
\text { Equality of } \\
\text { Variances }\end{array}$} & \multicolumn{7}{|c|}{ t-test for Equality of Means } \\
\hline & & \multirow[t]{2}{*}{$\mathrm{F}$} & \multirow[t]{2}{*}{ Sig. } & \multirow[t]{2}{*}{$\mathrm{t}$} & \multirow[t]{2}{*}{ df } & \multirow[t]{2}{*}{$\begin{array}{l}\text { Sig. } \\
\text { (2-tailed) }\end{array}$} & \multirow[t]{2}{*}{$\begin{array}{l}\text { Mean } \\
\text { Difference }\end{array}$} & \multirow[t]{2}{*}{$\begin{array}{l}\text { Std. Error } \\
\text { Difference }\end{array}$} & \multicolumn{2}{|c|}{$\begin{array}{l}95 \% \text { Confidence } \\
\text { Interval of the } \\
\text { Difference }\end{array}$} \\
\hline & & & & & & & & & Lower & Upper \\
\hline & $\begin{array}{l}\text { Equal } \\
\text { variances } \\
\text { assumed }\end{array}$ & .565 & .453 & 1.518 & 231 & .130 & .13945 & .09186 & -.04153 & .32044 \\
\hline ATTITUDE & $\begin{array}{l}\text { Equal } \\
\text { variances } \\
\text { not } \\
\text { assumed }\end{array}$ & & & 1.522 & 230.773 & .129 & .13945 & .09160 & -.04103 & .31994 \\
\hline
\end{tabular}

\section{Discussion and Implications}

Junk food is a growing phenomenon in India. This category is fast expanding its footprint despite Indian food habits are determined by social and family influences. In this limited study an attempt was made to explore influence of attitude, subjective norm and perceived behavioral control on intention to engage in junk food consumption. The attitude and social norms were not found to be a hold a significant influence. This probably demonstrates victory of junk food marketing which has managed to turn attitude around and managed to establish legitimacy of junk food eating. The social pressure to adhere to conventional food appears to be waning. The influence of PBC on intention points at the ease with which junk food could be accessed. On the second aspect of the study, the search related to junk food has not produced statistically significant difference between two groups. It seems information priming failed to produce corresponding expected influence on attitudes in the experimental group.
It seems tactical approach of reminding or drawing attention to harmful consequences of undesirable behaviors just before behavioral engagement fails to produce attitude change powerful enough to alter intentions. Instead, counter marketing should focus on bringing durable attitude change against socially undesirable behaviors.

The implications of this study are manifold for groups that seek to reverse rising incidence of junk food. The disconnection between attitude and intention implies that negative attitude fails to drive intentions to not consume junk food. The junk food brands succeed by subverting consumer attention away from negative objective appraisals by creating irresistible urges. The counter strategy therefore must build equally strong emotional appeals to drive intentions away from junk foods. Tactically, the communication can focus on how junk foods inflict harm on the self and through self on important others. For instance, anti-smoking campaigns show how a smoker's bad health has disastrous effect on loved ones. Further, the lack of influence of subjective norms of intention suggests that 
perception of disapproval by peer groups does not have strong influence. Norms operate by engendering feelings of embarrassment, shame and anxiety (Elster, 1994). The counter efforts must focus on finding ways as to how shame could be leveraged to reverse junk food eating by creating a perception of disapproval by important others. The perception of disapproval by reference groups could be effective in putting pressure against junk food consumption. For example, the fitness trend owes its success to emergence of gymming as a new social norm (Tousignant, 2017).

Finally, this study found how much one thinks one is in control of one's behavior significantly determines intentions to engage or not engage in junk food consumption. The conditions must be created that impair junk food intentions by imposing restrictions and simultaneously ensuring easy access of healthy alternatives. It is particularly illuminating to note how junk food brands succeed by enhancing ease of access by reaching within arm's reach of desire' (The Financial Times, 2015). The counter efforts may focus on creating ease of access to alternative foods.

This study contributes to our understanding that perceived behavioral control is the variable to influence to achieve an intention shift. Eliminating barriers and increasing availability of healthy alternatives to junk food are essential for a sense of sense of control to develop (Fila \& Smith, 2006). The self-belief and perceived ease of healthy alternatives have significant influence on intentions. For instance, anti-smoking campaigns promote belief among smokers that it is possible to quit smoking and at the same time render buying cigarettes difficult. Other studies also support the role of PBC in contest of healthy food consumption (Povey et al., 2000; Sjoberg et al., 2004) and fast food (Seo et al., 2011).

This study revealed a significant relationship between intention and behavior. This implies that once the intention to consume junk food is made, it is actualized by junk food consumption. Intentions are powerful predictors of behavior (Ajzen, 2001). The impact of intentions on behavior is also supported by behavior reasoning theory (Westaby, 2005). A metaanalytic analysis of correlation found a high correlation between intentions and behavior; this shows predictive utility of intentions for behavior (Sheppard et al., 1988).

\section{Conclusion}

The junk food has been making fast inroads in to a traditions based culture like India where concept of food is socio-culturally defined. Junk food consumption is linked with several health related issues. This study examined the influence of three antecedents on intentions based on TPB which is commonly used despite criticisms (Lee et al., 2010; McEachan et al., 2011). Few studies have investigated food related themes in India like fast food, obesity, and choice (Anand, 2011; Goyal \& Singh, 2007; Goyal et al., 2011). In addition, it was also probed whether cues that seek to alter intentions at the point of action have positive effects. Out of all antecedents, only perceived behavioral control was found to be a significant predictor of intentions. The agencies engaged in countering incidence of junk food must focus on building self-belief among consumers that one can live without junk food and increase barriers to its access. However, attitude and subjective norms were found not to drive intentions. This was not consistent with theory. Some factors seem to vitiate these relationships. The future research may explore reasons why these relationships do not hold valid. Further, it is an interesting area of inquiry to establish whether the influence of social norms is location dependent. Also, research should determine the relative importance of components making perceived behavioral control in driving intentions. The findings of this study are indicative and may not be generalized because of sampling limitations. The responses were obtained on a structured questionnaire which is an efficient but not 
effective method of data collection. The study was conducted at Delhi University Campus on a limited sample which may not adequately represent all diversities.

\section{References}

Ajzen, I. (1985). From intentions to actions: A theory of planned behavior. In J. Kuhl and J. Beckmann (Eds.), Action control: From cognition to behavior (pp. 11-39). Berlin, Heidelber, New York: SpringerVerlag.

Ajzen, I. (1988). Attitudes, personality and behavior. Milton keynes, Open University Press.

Ajzen, I. (2001). Nature and operation of attitudes. Annual review Psychology, 52: 27-58.

Ajzen, I. (2006). Constructing a TPB Questionnaire: Conceptual and Methodological Considerations. Retrievedfrom http://www.people. umass.edu/aizen/pdf/tpb.measurement. pdf (accessed on 15 May, 2018).

Ajzen, I. (2015). Consumer attitudes and behavior: The theory of planned behavior applied to food consumption decisions. Italian Review of Agricultural economics, Anno LXX (2): 121-138.

Ajzen, I., \& Madden, T. J. (1986). Prediction of goal directed behavior; Attitudes, intentions and perceived behavioral control. Journal of Experimental Social Psychology, 22(5): 453-474.

Anand, R. (2011). A study of determinants impacting consumers' food choice with reference to the fast food consumption in India. Society and Business Review, 6(2): 176-187.

Anderson, J. R. (1983). The Architecture of Cognition. Cambridge, MA: Harvard University Press.

Appadurai, A. (1988). How to make a National Cuisine: Cookbooks in Contemporary
India?Comparative Studies in Society and History, 30(1): 3-24.

Armitage, C. J. \& Conner, M. (2001). Social cognitive determinants of blood donation. Journal of Applied Social Psychology, 31:1431-1457.

Aronson, E., \& Gonzales, M. H. (1990). Alternative social influence processes applied to energy conservation. In J. Edwards, R. S. Tindale, L. Heath, \& E. J. Posaval (Eds.), Social influences: Processes and prevention (pp. 301-325). New York: Plenum.

Arumugam, B. et al. (2015). Fast Food Addiction: The junk enslavement. International Archives of Integrated Medicine, 2(1): 62-7.

Bagozzi, R. P., Wong, N., Abey, S. \& Bergami, M. (2000). Cultural and situational contingencies and the theory of reasoned action: Application to fast food restaurant consumption. Journal of consumer psychology, 9(2): 97-106.

Berg, L. (2016). Junk Food Facts: New Resources for Nutrition Educators. Journal of Nutrition, Education and Behavior, 48:158.e3.

Bhaskar, R. (2012). Junk food: Impact on health. Journal of Drug Delivery \& Therapeutics, 2(3): 67-73.

Birch, L. L. (1988).The relationship between children's food preferences and those of their parents. Journal of Nutrition Education, 12: 14-18.

Birch, L. L. \& Anzman, S. L. (2010). Learning to eat in an obesogenic environment: A developmental systems perspective on childhood obesity. Child Development Perspectives, 4: 138-143.

Bowman, S. A. et al. (2004). Effects of fastfood consumption on energy intake and diet quality among children in a national house-hold survey. Pediatrics, 113: 11218.

Brownell, K. D. et al. (2009). The need for bold action to prevent adolescent obesity. 
Journal of Adolescent Health, 45: S8S17.

Business Standard. (2016). In a first, Kerela imposes $14.5 \%$ fat tax on junk food. Retrieved from http://www.businessstandard.com/article/economy-policy/ in-a-first-kerala-imposes-14-5-fat-taxon-junk-food-116070800480_1.html (accessed on 1 March, 2018).

Carmack, C. C., \& Lewis-Moss, R. K. (2009). Examining the theory of planned behavior applied to condom use: The effectindicator vs. causal-indicator models. The Journal of Primary Prevention, 30(6): 659-676.

Chaplin, H. (1999). Food fight! Am Demographics, 21(6): 64-65.

Cohen, L. \& Manion, L. (1980). Research Methods (1st ed.). London: Croom Helm.

Collins, A. M., \& Loftus, E. F. (1975). A spreading-activation theory of semantic processing. Psychological Review, 82(6): 407-428.

Conner, M. \& Armitage, C. J. (1988). Extending the theory of planned behavior: A review and avenues for future research. Journal of applied Social Psychology, 28(15): 1429-1464.

Costanzo, M., Archer, D., Aronson, E., \& Pettigrew, T. (1986). Energy conservation behavior: The difficult path from information to action. American Psychologist,41: 521-528.

Crisp, L. N. (2016). One world health: An overview of global health. Taylor \& Francis: Baca Raton, FL.

Cronin, J. M. \& McCarthy, M. B. (2011). Fast food and fast games: An ethnographic exploration of food consumption complexity among the videogames subculture. British Food Journal, 113(6): 720-743.

Datar, A. \& Nicosia, N. (2012). Junk food in schools and childhood obesity. Journal of Policy Analysis and Management, 31(2): 312-337.

Dennison, C. M., \& Shepherd, R. (1995). Adolescent food choice: An application of the theory of planned behaviour. Journal of Human Nutrition and Dietetics, 8: 9-23.

Donovan, R. \& Henley, N. (2003). Social marketing: Principles and practice. Melbourne: IP Communications.

Duggal, E., \& Verma, H. V. (2016). Air pollution and Odd-Even Scheme from the perspective of theory of reasoned action. Pacific Business Review International, 9(5): 46-56.

Dutta, K., \& Singh, S. (2014). Applying the theory of planned behavior to understand Indian housewives' purchase behavior towards healthy food brands. IUP Journal of Brand Management, 11(4): 7-28.

Dutta, K., \& Singh, S. (2014). Applying the theory of planned behavor to understand Indian housewives' purchase behavior healthy food brands. The IUP journal of Brand Management, 11(4): 7-23.

Eagly, A. H., \& Chaiken, S. (1993). The psychology of attitudes. Harcourt Brace: Jovanovich College Publishers.

Elster, J. (1994). Rationality, emotions and social norms. Synthese, 98(1): 21-94.

Engle, J. F., Blackwell, R. D., \& Minard P. W. (1995). Consumer behavior. NY: The Dryden Press.

Ettinger, J. (2014). Regulate fast foods, reverse obesity: World Health Organization urges nations. Retrieved from http:// www.organicauthority.com/regulatefast-foods-reverse-obesity-world-healthorganization-urges-nations/ (accessed on 21 March, 2018).

Fila, S. A., \& Smith, C. (2006). Applying the Theory of Planned Behavior to healthy eating behaviors in urban Native American youth. The International Journal of Behavioral Nutrition and Physical Activity, 3(11): 1-10.

Fineberg, H. V. (2006). Changing the trends: Food marketing to children and youth. Medscape General Medicine, 8(2): 14.

Finkelstein, E. A., Ruhm, C. J., \& Kosa, K. M. (2005). Economic causes and 
consequences of obesity. Annual Review of Public Health, 26(1): 239-257.

Fishbein, M., \& Ajzen, I. (1980). Belief, attitude, intention and behavior. Reading, Massachusetts: Addison-Wesley.

Fuller, K. (2017). Eating habits in the Indian culture. Retrieved from https://www. classroom.synonym.com(accessed on 15 March, 2018).

Gardner, R. E., \& Hausenblas, H. A. (2005). Exercise and diet determinants of overweight women participating in an exercise and diet program; a prospective examination of the Theory of Planned Behavior. Women and Health, 42(4): 3762.

Giles, M., \& Cairns, E. (1995). Blood donation and Ajzen's theory of planned behaviour: An examination of perceived behavioural control. British Journal of Social Psychology, 34: 173-188.

Giles, M., McClenahan, C., Cairn, E., \& Mallet, J. (2004). An application of the Theory of Planned Behavior to Blood donation: The importance of self-efficacy'. Health Education Research: Theoryand Practice, 19(4): 380-391.

Gohain, M. (2017, Oct. 26). Fast track to diabetes? $40 \%$ of class III-IV kids prefer junkfood. Times of India (p. 23) (accessed on 15 March, 2018).

Gordon, R., Russell-Bennett, R., \& Lefebvre, R. C. (2016). Social marketing: The state of play and brokering the way forward. Journal of Marketing Management, 32(11/12): 1059-1082.

Goyal, A., \& Singh, N. P. (2007). Consumer perception about fast food in India: An exploratory study. British Food Journal, 109(2): 182-195.

Goyal, J. P., Kumar, N., Parmar, I., Shah, V. B., \& Patel, B. (2011). Determinants of overweight and obesity in affluent adolescent in Surat City, South Gujarat region, India. Indian Journal of Community Medicine, 36(4): 296-300.
Goyal, R. K. et al. (2010). Prevalence of overweight and obesity in Indian adolescent school going children: Its relationship with socioeconomic status and associated lifestyle factors. Journal of the Association of Physicians of India, 58:151-8.

Grønhøj, A., Bech-Larsen, T., Chan, K., \& Tsang, L. (2012).Using Theory of Planned Behavior to predict healthy eating among, Danish adolescents.Health Education, 113(1): 4-17.

Hartwick, J., \& Barki, H. (1994). Explaining the role of user participation in information system use. Management Science, 40(4): 440-465.

Hastings, G. (2003). Social marketers of the world unite, you have nothing to lose but your shame. The Marketing Quarterly, 9(4): 14-21.

Hawkes, C. (2002). Marketing activities of global soft drink and fast food companies in emerging markets: A review. In Globalization, Diets, and NonCommunicable Diseases, Geneva: World Health Organization.

He, M., Tucker, P., Gilliland, J., Irwin, J. D., Larsen, K., \& Hess, P. (2012).The influence of local food environments on adolescents' food purchasing behaviors. International Journal Environmental Research and Public Health, 9(4): 14581471.

Herman, C. P., Roth, D. A., \& Polivy, J. (2002). Effects of the presence of others on food intake: A normative interpretation. Psychological Bulletin, 129: 873-886.

Higgins, T. E., Rholes, W. S., \& Jones, C. R. (1977). Category accessibility and impression formation. Journal of Social Psychology, 13: 141-154.

Hu, L. T., \& Bentler, P. M. (1999). Cut-off criteria for fit indexes in covariance structure analysis: Conventional criteria versus new alternatives. Structural Equation Modeling, 6(1): 1-55. 
Institute of Medicine (2006). Food marketing to children and youth: Threat or opportunity? Washington, DC: The National Academies Press. Retrieved from https://doi.org/10.17226/11514.

International Social Marketing Association, European Social Marketing Association, \& Australian Association of Social Marketing (2013). Consensus Definition of Social Marketing. Brisbane: ISMA, ESMA and AASM.

Isobel, R. C., Williams, S. S., Michela, J. L., \& Franklin, A. B. (2006).Understanding the food choice process of adolescents in the context of family and friends. Journal of Adolescent Health, 38(5): 575 - 582.

Jaisheeba, A. A., Sornaraj, R., \& Gayathri, K. (2012). Influence of westernized culture and changed dietary habits on the BMI status of the school children of Tirunelveli. International Journal of PharmTech Research, 4: 1065-77.

Jha, D. N. (2017, Nov. 1). Why 2 out of 10 school kids in Delhi are overweight. Times of India, pp. 4.

Joreskog, K. G., \& Sorbom, D. (1996). "LISREL8 User's reference Guide.SSI.

Kalra, S., \& Unnikrishnan, A. G. (2012). Obesity in India: The weight of the nation. Journal of Medical Nutrition and Nutraceuticals, 1(1): 37-41.

Kaushik, J. S., Narang, M., \& Parakh, A. (2011). Fast food consumption in children. Indian Pediatrics, 48: 97-101.

Khan, U., Dhar, R., \& Wertenbroch, K. (2005).A behavioral decision theory perspective on hedonic and utilitarian choice. In S., Ratneshwar \& D., Glen Mich, D. (Eds), Consumption: Frontiers of Research on Consumer Motives, Goals, and Desires (pp. 144-65). London: Routledge.

Khandelwal, S., \& Reddy, K. S. (2013). Eliciting a policy response for the rising epidemic of overweight-obesity in India. Obesity Reviews, 14: 114-125.

Kihara, S., \& Matsuzawa, Y. (2015). Fat distribution and cardiovascular disease risk. Current Cardiovascular Risk Reports, 9(3): 1-6.

Knabe, A. (2009). Applying Ajzen's Theory of Planned Behavior to a Study of Online Course Adoption in Public Relations Education. Doctoral dissertation, Marquette University.

Kotler, P., \& Armstrong G. (2004). Principles of Marketing (10th ed.). Upper Saddle River, NJ: Prentice Hall.

Kotler, P. and Lee, N. (2008). Social marketing: Influencing behaviors for good (3rd ed). CA: Sage, Thousand Oaks.

Kotler, P., \& Levy, S. J. (1971). Demarketing, yes, demarketing. Harvard Business Review, 49(6): 74-80.

Kotler, P., \& Zaltman, G. (1971). Social marketing: An approach to planned social change. Journal of Marketing, 35: 3-12.

Krugman, H. E. (1966). Answering some unanswered questions in measuring advertising effectiveness. Proceedings, 12th Annual Meeting (pp. 18-23). New York: Advertising Research Foundation.

Lee, J. L., Cerreto, F. A., \& Lee, J. (2010). Theory of Planned Behavior and teachers' decisions regarding use of educational technology.Educational Technology and Society, 13(1): 152-164.

Lefebvre, R. C. (2011). An integrative model for social marketing. Journal of Social Marketing, 1(1): 54-72.

Livingstone, S. (2005). Assessing the research base for the policy debate over the effects of food advertising to children. International Journal of Advertising, 24(3): 273-296.

Lourenço, J. S., Ciriolo, E., Almeida, S. R., \& Troussard, X. (2016b). Behavioural insights applied to policy: European report. Luxembourg, EUR 27726 EN. doi:10.2760/903938.

MacFayden, L., Stead, M., \& Hastings, G. B. (1999). Social marketing: A synopsis. Strathclyde: The Centre for Social Marketing. 
Marino, J. (2004, Februaury 10). Prescriptionstrength chocolate. Science News, 255.

McEachan, C., Conner, M., Taylor, N., \& Lawton, R. (2011). Prospective prediction of health-related behavior with the TPB: A meta-analysis. Health Psychology Review, 5(2): 97-144.

Miller, K. S., Boyer, C. B., \& Cotton G. (2004). The STD and HIV epidemics in African American youth: Re-conceptualizing approaches to risk reduction. Journal of Black Psychology, 30(1): 124-137.

Munro, D. D. (2013). Sugar Linked To \$1 Trillion in U.S. Healthcare Spending, Forbes. Retrieved from https://www.forbes. com/sites/danmunro/2013/10/27/sugarlinked-to-1-trillion-in-u-s-healthcarespending/\#1dddda16ad1a (accessed on 1March, 2018).

Mytton, O., \& Rayner, M. (2012). A tax on sugary drinks would not be a panacea but it would be a sensible step in the right direction for public heal. Retrieved from http://blogs.lse.ac.uk/politicsandpolicy/ tax-on-sugary-drinks/ (accessed on 1March, 2018).

National Institute of Nutrition. (2010). National Institute of Nutrition Dietary guidelines for Indians: A manual (2nd ed.). Hyderabad: National Institute of Nutrition.

NDTV. (2017). The bad, the worse, 5 ways junk food can mess with your brain. Retrieved from http://food.ndtv.com/lists/the-badthe-worse-5-ways-junk-food-can-messwith-your-brain-764392 (accessed on 1 March, 2018).

Nunnally, J. C. (1978). Psychometric Theory ( $2^{\text {nd }}$ ed.). New York: McGrawHill Book Company.

Ogden, C. L., \& Carroll, M. D. (2010). Prevalence of high body mass index in US children and adolescents, 20072008. The Journal of American Medical Association, 303(3): 242-249.

Povey, R., Conner, M., Sparks, P., James, R., \& Shepherd, R.(2000). The theory of planned behaviour and health eating: Examining additive and moderating effects of social influence variables. Psychology and Health, 14: 991-1006.

Raloff, J. (1996).....but we eat it for pleasure. Science News, 150(12): 235.

Resseler, R. C. (2013). World Health Organization: Marketing Junk Food to Kids Has Been 'Disastrously Effective. Retrieved from https://thinkprogress.org/ world-health-organization-marketingjunk-food-to-kids-has-been-disastrouslyeffective-975b5f89cdc1/ (accessed on 20 March, 2018).

Reynolds, K. J., Subašić, E., \& Tindall, K. (2014). The problem of behaviour change: From social norms to an in group focus. Social and Personality Psychology Compass, 1-12. Retrieved from http:// doi.org/ 10.1111/spc3.12155 (accessed on 15 March, 2018).

Robinson, R., \& Smith, C. (2002). Psychosocial and demographic variables assoicated with consumer intention to purchase sustainable produced foods as defined by the Midwest Food Alliance. Journal of Nurtition Education and Behavior, 34(96): 316-325.

Rozin, P., Fallon, A., \& Mandell, R. (1984). Family resemblance in attitude to foods. Developmental psychology, 20: 309-314.

Ryan, M. J., \& Bonfield, E. H. (1980). Fishbein's intention model: A test of external and pragmatic validity. Journal of Marketing, 44: 82-95.

Sahadi, J. (2015). Should there be a fat tax on soda and junk food? Retrieved from http://money.cnn.com/2015/12/14/pf/ taxes/fat-tax-soda-sugar/ (accessed on 3 March, 2018).

Schifter, D. E., \& Ajzen, I. (1985). Intention, perceived control and weight loss: an application of the Theory of Planned Behavior. Journal of Personality and Social Psychology, 49(3): 843-851.

Schlosser E. (2001). Fast Food Nation. The Dark Side of the All-American Meal. Boston, MA: Houghton Mifflin Company. 
Schor, J. B., \& Ford, M. (2007). From tastes great to cool: Children's food marketing and the rise of the symbolic. Journal of Law, Medicine \& Ethics, 35(1): 10-21.

Schwartz, S. H. (1994). Are there universal aspects in the structure and Content of Human Values. Journal of Social Issue, 50(4): 19-45.

Seo, H., Lee, S.-K., \& Nam, S. (2011). Factors influencing fast food consumption behaviors of middle-school students in Seoul: An application of theory of planned behaviors. Nutrition Research and Practice, 5(2): 169-178. Retrieved from http://doi.org/10.4162/nrp.2011.5.2.169.

Shakiran, D. R. (2012). Fast foods and their impact on health. Journal of Krishna Institute of Medical Sciences University, 1: 7-15.

Sheppard, B. H., Hartwick, J., \& Warshaw, P. R. (1988). The theory of reasoned action: A meta-analysis of past research with recommendations for modifications and future research, Journal of Consumer Research, 15, 325-343.

Sjoberg, S., Kim, K., \& Reicks, M. (2004). "Applying the Theory of Planned Behavior to Fruit and Vegetable Consumption by Older Adults". Journal of Nutrition for the Elderly, 23: 35-46.

Smith, A. F. (2006). Encyclopedia of junk food. Greenwood Publications.

Smith, A. F. (2007). The Oxford companion to American food and drink. Oxford University Press, Oxford: New York.

Srinivas, T. (2006). As mother made it: The cosmopolitan Indian family, authentic food, and construction of cultural Utopia. International Journal of Sociology of The Family, 32(2): 191-221.

Stanley, W. C., Shah, K. B., \& Essop, M. F. (2009). Does junk food lead to heart failure? Importance of dietary macronutrient composition in hypertension. Hypertension, 54: 12091210.

Stender, S., Dyerberg, J., \& Astrup, A. (2007). Fast food: Unfriendly and unhealthy.
International Journal of Obesity, 31: 887-890.

The Financial Times. (2015). Within arm's reach of desire. Retrieved from https:// www.ft.com/content/f0f57086-bb7611e4-b95c-00144feab7de.

Tonglet, M., Phillips, P. S., \& Read, A. D. (2004).Using the Theory of Planned Behavior to investigate the determinants of recycling behavior: A case study from Brixworth, UK. Resources, Conservation and Recycling, 41: 191-214.

Tousignant, L. (2017, May 22). Alien yoga is the latest 'WTF' Instagram trend. http:// www.news.com.au/lifestyle/fitness/ exercise/alien-yoga-is-the-latest-crazeamong-fitness-fans-on-social-media/ news-story/2d310bf40b76711f3213d73c $707 \mathrm{bd} 748$.

Triandis, H. C. (1994). Culture and social behavior. New York: McGraw Hill.

Vadehra, S. (2010).Advertising to children in India. Young Consumers, 4: 75-78.

Varman, R. (2017). Curry. Consumption Markets \& Culture, 20(4): 350-356.

Vermeir, I., \& Verveke, W. (2006). Sustainable food consumption: Exploring the consumer 'attitude- behavioral intention' gap'. Journal of Agricultural and Environmental Ethics, 90: 169-194.

Wang, Y., Chen, H. J., Shaikh, S., \& Mathur, P. (2009). Is obesity becoming a public health problem in India? Examine the shift from under to overnutrition problems over time? Obesity Reviews, 10: 456-474.

Westaby, J. D. (2005). Behavioral reasoning theory: Identifying new linkages underlying intentions and behavior, Organizational Behavior and Human Decision Processes, 98, 97-120.

Wheaton, B. et al. (1977). Assessing Reliability and Stability in Panel Models. Sociological Methodology, 8(1): 84-136.

Witkowski, T. H. (2007). WittFood marketing and obesity in developing countries: Analysis, ethics, and public policy. Journal of Macro Marketing, 27(2): 126137. 